\title{
Youth Unemployment AND CAREER SCARRING: SOCIAL-PSYCHOLOGICAL Mediating Effects? ${ }^{1}$
}

\author{
HARVEY KRAHN \\ Angela Chow
}

Abstract. Unemployment has career scarring effects for adults, and sometimes for youth, but previous research has not directly demonstrated how this occurs. This 14-year (1985-99) longitudinal study reveals that cumulative unemployment between age 18 and age 32 has a negative effect on both total income and quality of employment at age 32 . This scarring effect is not mediated by parallel changes in self-esteem, perceived control or extrinsic work values. Labour market mechanisms, rather than social psychological processes, are likely responsible for the career scarring effect of youth unemployment.

Keywords: Youth Unemployment, Scarring, Quality of Employment, Selfesteem, Perceived Control, Work Values

Résumé. On constate que le chômage des adultes laisse des séquelles sur la carrière. C'est parfois le cas pour les jeunes aussi. Mais la recherche en date ne montre pas quel mécanisme est impliqué. La présente étude longitudinale sur 14 ans (1985-1999) révèle qu'un chômage cumulé entre l'âge de 18 ans et de 32 ans a un effet négatif sur le revenu total, ainsi que sur la qualité de l'emploi à l'âge de 32 ans. Ces séquelles ne passent pas par une fluctuation parallèle de l'estime de soi, du sentiment d'avoir le contrôle ou des valeurs intrinsèques relatives au travail. Les séquelles sur la carrière laissées par le chômage des jeunes tiennent probablement aux mécanismes du marché du travail, plutôt qu'à des processus psychologiques sociaux.

Mots cles: Le chômage des jeunes, les cicatrices, la qualité de l'emploi , l'estime de soi, le contrôle perçu, valeurs de travail

1. Correspondence should be directed to the first author: harvey.krahn@ualberta.ca. Funding was provided by the Social Sciences and Humanities Research Council of Canada (SSHRC), Alberta Advanced Education, and the University of Alberta. Angela Chow was supported by a SSHRC Banting Postdoctoral Fellowship. Data were collected by the Population Research Laboratory, University of Alberta. Useful comments on an earlier draft from Nancy Galambos and three anonymous CJS reviewers improved this paper. 


\section{INTRODUCTION}

을 esearch spanning many decades has documented negative social 1 Sand psychological effects of unemployment for adults (e.g., Jahoda 1982; Dooley et al. 1996; Paul and Moser 2009), including long-term career-damaging outcomes often described as "scarring." Extensive unemployment can lead to further unemployment, lower income, and lower quality jobs later in life (e.g., Arulampalam 2001; Dieckhoff 2011; Antonini and Bühlmann 2015).

During the 1980s and 1990s, when youth unemployment was particularly high in many western societies (Fevre 2011), commentators also predicted scarring effects for youth. Some European studies have documented increased unemployment and lower earnings in adulthood (Cockx and Pichhio 2012; Franzen and Kassman 2005; Gregg and Tominey 2005; Luijkx and Wolbers 2009), as did a recent study focusing on Brazil and Argentina (Cruces et al. 2012). American studies, however, have not consistently revealed scarring effects (Burgess et al. 2003; Gardecki and Neumark 1998; Ryan 2001).

Cross-national studies (e.g., Gangl 2004, 2006) have explored factors (e.g. labour legislation, unemployment insurance) that might moderate the long-term scarring effects of unemployment, asking whether and why the scarring effect of unemployment varies across different settings. Few researchers, however, have systematically assessed the possible mediating factors that might account for the association between early unemployment and later career scarring. In other words, whether focusing on youth or adult unemployment, previous research has seldom asked exactly how and why it might lead to career scarring.

This study uses 14-year (1985-99) Canadian longitudinal data to ask whether cumulative unemployment between the ages of 18 and 32 had a scarring effect on young adults' income as well as their quality of employment. Finding a scarring effect for both, the paper then enquires whether changes between age 18 and 32 in perceived control, self-esteem, and extrinsic work values are perhaps responsible, since previous research has highlighted how they can be affected by unemployment. Multivariate analyses reveal that these social psychological changes do not mediate the scarring impact of youth unemployment, leading to the conclusion that labour market mechanisms are likely more responsible. Given current high levels of youth unemployment and underemployment, evidence of career scarring from a study completed 15 years ago continues to have policy relevance today. 


\section{Historical Context}

Employment patterns changed dramatically in North America in the last decades of the $20^{\text {th }}$ century. Many large work organizations downsized and restructured. Part-time and temporary work became more common, particularly for youth (Krahn, Hughes and Lowe 2015). Average incomes for young Canadian workers declined, relative to those of older workers (Chung 2006). Youth unemployment soared to around $20 \%$ during the recession of 1981-82, dropped, and then rose again during the 1990-92 recession (Figure 1).

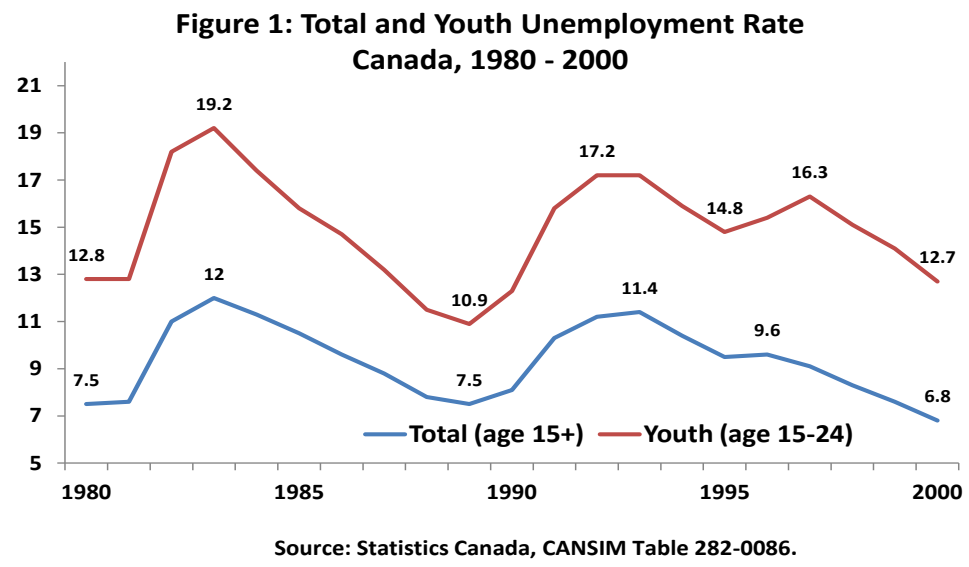

Compared to the cohorts preceding them, young people leaving school in the 1980s and 1990s experienced a delayed and more difficult transition into the adult labour market (Marquardt 1998; Ryan 2001; Shanahan 2000). Some media commentators, politicians, and academics were alarmed, suggesting that the current generation was being short-changed and might, indeed, be permanently "scarred" in terms of career prospects.

\section{Theoretical Explanations of Unemployment's Career-Scarring EFFECTS}

\section{Labour Market Mechanisms}

Most studies of career scarring have referenced human capital and/or signaling theory to explain the phenomenon (Brand 2006; Cockx and Picchio, 2012; Dieckhoff 2011; Gregg and Tominey 2005; Luijkx and 
Wolbers 2009; Mroz and Savage 2006; Schmelzer 2011). Human capital depreciation might occur since, compared to those with jobs, both the firm-specific and general skills of the unemployed might become "rusty." In addition, the unemployed cannot receive on-the-job training, as might some of their employed peers. Signaling theory hypothesizes that, when making hiring or promotion decisions, employers discriminate against the previously unemployed because their resumes, punctuated by periods of unemployment, signal that they might be unreliable workers (Burgess et al. 2003; Antonini and Bühlmann 2015). Social capital theory offers a third labour market-focused explanation. Repeated and long-term experience of unemployment could reduce the number of contacts and networks an individual could use to find better jobs (Diechoff, 2011; Gallie et al., 2003; Gangl, 2006).

There have been almost no direct tests of labour market-focused explanations. While human capital depreciation is plausible, it would be very difficult to measure in large sample surveys. Social capital deficits might be inferred from survey data on job search behaviour, but do not appear to have been directly measured. As for discriminatory behaviour of employers, systematic studies with linked employer-job applicant data do not appear to exist. This paper is also unable to directly test scarring explanations that focus on labour market mechanisms. Instead, it focuses on an alternative explanation, asking whether social psychological mediating factors might be responsible.

\section{Social Psychological Mediating Effects}

Previous longitudinal research has shown adult unemployment associated with increased depression, reduced self-esteem, greater feelings of powerlessness, and poorer health among adults (Breslin and Mustard 2003; Dooley et al. 1996). Meta-analyses reveal sizeable effect sizes (Murphy and Athanasou 1999; Paul and Moser 2009). Longitudinal studies of youth unemployment and mental health have reported mixed results. Some have replicated research with adults (e.g., Dooley et al. 2000; Goldsmith et al. 1996; Hartnagel and Krahn 1995; Mossakowski 2009; Prause and Dooley 1997), while others have shown limited or no negative effects (e.g., Breslin and Mustard 2003; Fergusson et al 2001; Patterson and Mean 1997). These mixed findings might reflect different study designs, or cultural and institutional differences across countries. Alternatively, perhaps unemployment is somewhat less psychologically troubling for youth (Fryer 1997).

To the extent that unemployment does have negative mental health consequences for youth, social psychological changes might help ex- 
plain the career scarring observed in some studies (Franzen and Kassman 2005; Gregg and Tominey 2005; Luijkx and Wolbers 2009). Lower self-esteem and reduced perceived control due to unemployment could translate into less effective job search (Wanberg et al. 2005). Unemployment has been associated with reduced occupational aspirations among youth (Empson-Warner and Krahn 1992), and might lead young adults to place less value on extrinsic work rewards (e.g., income and job security) as they realize that high quality jobs are in scarce supply (Johnson 2002). In turn, they might be less inclined to keep looking for "good jobs," and more willing to accept lower-paying and less secure jobs. Clark et al. (2001) refer to such psychological mechanisms as a process of "habituation," proposing that "if unemployment becomes the norm for an individual, then there is a reduced incentive to try to change one's labour force status" (221).

Perhaps because of absent psychological data in most scarring studies, such mediating mechanisms have not been previously explored, with one exception. Hammer (1997) proposed that "history dependence in youth unemployment" (i.e., career scarring) might be explained with structural explanations (e.g., youth being trapped in temporary and insecure jobs), cultural explanations (e.g., a sub-culture of unemployed alienated youth placing less value on paid work), and individual explanations (e.g., unemployed youth experiencing mental health problems which could lead to further unemployment). In his eight year (1985-1999) longitudinal study of Norwegian youth, Hammer (1997) concluded that employment in insecure jobs might be partially responsible for career scarring. Individual factors (i.e., mental health, measured concurrently with outcome measures) also had some impact. He did not, however, directly test the hypothesis that social psychological changes mediate unemployment's scarring effects.

\section{Research Questions}

We analyze data from a 14 year (1985-99) longitudinal study to ask whether cumulative unemployment between age 18 and 32 had career scarring effects for Canadian youth. This question needs to be asked, given conflicting findings about long-term career scarring in the youth unemployment literature. We use two dependent variables, personal income and a "quality of employment" index. A second research question asks whether change in psychological states (self-esteem, perceived control, extrinsic work values) that may have resulted from experiences of unemployment mediates any of its observed scarring effects. This 
second question is equally important, since the unemployment and mental health literature points to a very plausible hypothesis, namely, that psychological changes resulting from unemployment might mediate its effect on career outcomes. We go well beyond Hammer's (1997) study by covering a longer time period (14 years compared to 8 ), employing two dependent variables, and using change (rather than concurrent) measures to test the mediating variables hypothesis.

\section{Sample Characteristics}

In mid-1985, 983 Edmonton high school seniors (age 17 to 18) from six schools in both middle- and working-class neighbourhoods completed questionnaires in class in the Edmonton Transitions Study baseline survey. Ninety-one percent $(\mathrm{n}=894)$ provided contact information. Just over half (52\%) were male, and $80 \%$ were born in Canada. Fifteen percent self-reported their ethnic/racial status as non-White. Ten percent came from families where both parents had a university degree; another $16 \%$ reported that one parent had completed university. Comparisons to census data (McVey \& Kalbach 1995) indicate that the sample was generally representative of western Canadian urban youth born in the late 1960s on race, immigration status, and parents' education.

In 1999, 509 follow-up telephone interviews were completed (response rate of $52 \% ; 57 \%$ of those who provided contact information in 1985). Female respondents and those with higher baseline educational aspirations were somewhat more likely to remain in the study. By 1999 (age 32), 12\% of the sample had completed an apprenticeship and 15\% had acquired a community college diploma. One-third (32\%) had obtained a technical school diploma, and a similar proportion (31\%) had completed a university degree. Almost two-thirds (59\%) were married or co-habiting $(8 \%)$, and almost half (48\%) were parents.

Sample members reported an average of 10.0 years $(S D=3.6)$ of non-student employment between 1985 and 1999 (jobs held during a school term or in the summer were defined as "student jobs"). On average, they had held 4.4 non-student jobs $(S D=3.8)$ and had worked for 4.3 different employers $(S D=4.0)$. At age $32,87 \%$ were employed $(94 \%$ of men; $81 \%$ of women). The unemployment rate among 1999 sample members was $4 \%$, similar to the provincial unemployment rate for young adults (see Krahn, Howard and Galambos 2015 for additional information about this study).

At age $32,74 \%$ of study participants were holding a single job; $13 \%$ were working in more than one job. Thirteen percent of employed re- 
spondents were working part-time, $5 \%$ held temporary jobs, and $16 \%$ were self-employed. Just under half (48\%) were in high status occupations (management, and natural science, health and education professions). The labour force profile of the 1999 sample (age 32) was very similar to that of the province as a whole.

\section{Measurement}

\section{Dependent Variables}

The 442 employed (including self-employed) study participants in the 1999 sample reported gross (before deductions) monthly income for their main job (and additional jobs, if applicable). Eleven percent did not answer the income questions. The remaining 392 reported an average monthly income (all jobs) of $\$ 3068(S D=\$ 1681)$, or approximately $\$ 36,800$ annually (Table 1 ). Responses were moderately positively skewed (1.385) so a square root transformation was employed (Tabachnick and Fidell, 2007). Additional analyses examining only main job income, as well as log transformed and Box-Cox transformed income, produced results very similar to those reported below.

Several previous scarring studies (Brand 2006; Dieckhoff 2011; Pollman and Buchel 2005) have used single-item quality of employment measures. We employ a quality of employment (QoE) cumulative index with seven binary components as our second dependent variable (see Lambda 2003 and Clark 2005 for similar index constructions). Scores of ' 1 ' were assigned if: the respondent was a manager or professional; was employed full-time; had a permanent job; had been promoted at least once in their current job; supervised others; received more than the (sample) average number of fringe benefits; and worked for an employer who provided formal training. QoE index values could range from 0 (low quality job) to 7 (high quality job).

Some of these job quality criteria (e.g., temporary jobs; receiving promotions) do not apply to the self-employed, so they (16\% of all employed) were omitted from the analysis of this second dependent variable. The average score on the QoE index for the 371 paid employees was $4.5(S D=1.6)$. Gross total income (square root transformed) and the QoE index were positively correlated $(r=0.528$; Appendix Table A). 
Table 1: Descriptive Statistics ${ }^{1}$

\begin{tabular}{|c|c|c|c|}
\hline Variables & Mean & $S D$ & $N$ \\
\hline Monthly income (1999, all jobs, \$) & 3068.29 & 1680.66 & 392 \\
\hline Quality of employment index (1999) & 4.51 & 1.55 & 371 \\
\hline Months unemployed (1985-99) & 5.06 & 9.47 & 509 \\
\hline Perceived control change (1985-99) & .10 & 1.28 & 509 \\
\hline Perceived control $(1985)^{2}$ & 3.99 & .97 & 957 \\
\hline Perceived control (1999) & 4.08 & 1.00 & 506 \\
\hline Self-esteem change (1985-99) & .30 & 1.02 & 509 \\
\hline Self-esteem $(1985)^{2}$ & 3.74 & .96 & 971 \\
\hline Self-esteem (1999) & 4.12 & .79 & 508 \\
\hline Extrinsic work value change (1985-99) & -.11 & .77 & 509 \\
\hline Extrinsic work value $(1985)^{2}$ & 4.26 & .64 & 982 \\
\hline Extrinsic work value (1999) & 4.14 & .65 & 509 \\
\hline Gender $($ female $=1)$ & .47 & .50 & 983 \\
\hline Parent(s)' education (degree $=1$ ) & .35 & .65 & 983 \\
\hline Academic HS program (yes $=1)$ & .61 & .49 & 983 \\
\hline Average grades in Grade 12 (1985) & 3.29 & .87 & 982 \\
\hline Weekly hours worked (1999, main job) & 40.92 & 12.40 & 442 \\
\hline Years since leaving home & 9.04 & 4.41 & 509 \\
\hline Parent by $1999($ yes $=1)$ & .50 & .50 & 509 \\
\hline Years FT post-sec education (1985-99) & 2.52 & 2.68 & 509 \\
\hline Union membership (yes $=1$ ) & .49 & .50 & 442 \\
\hline
\end{tabular}

1 Full Time 1 sample (1985; $N=983$ maximum) and /or Time 2 (1999) sample (N=509)

21985 values for the 509 study participants in 1999 are virtually identical.

\section{Unemployment}

At age $32,58 \%$ of sample members recalled being unemployed (i.e., out of work and actively looking for work) at least once since completing Grade 12 . The total sample (including the $42 \%$ who recalled no unemployment) reported an average of 1.4 spells $(S D=2.4)$ and 5.1 total months of unemployment $(S D=9.5)$. The $58 \%$ who had been unemployed at least once averaged 2.4 spells of unemployment and an average of 9.1 months. 
Social Psychological Change Measures

Three social psychological change variables were tested as possible mediators. In both the baseline (age 18) and the 1999 (age 32) surveys, respondents were asked how much they disagreed or agreed $(1=$ strongly disagree; 5 = strongly agree) that "I have little control over things that happen to me" (Pearlin and Schooler 1978). A change in perceived control variable was constructed by subtracting 1985 responses from 1999 responses. A change in self-esteem variable was constructed by subtracting 1985 answers (on the same 1 - 5 response scale) from 1999 responses to "on the whole, I am satisfied with myself," a single item from Rosenberg's (1979) self-esteem scale. Higher scores on both change measures indicated an increase in perceived control and self-esteem, respectively, between age 18 and age 32 .

In both the 1985 and the 1999 surveys, respondents were asked how important three work rewards (work that pays well; with little chance of being laid off; with good chances for promotion) would be when "looking for a full-time job today." Respondents answered on five-point scale $(1=$ not important at all; 5 = very important). For both 1985 and 1999, a three item "extrinsic work values" index was created by averaging responses. Inter-item reliability was satisfactory in 1985 (Alpha $=.535 ; \mathrm{n}$ $=975)$ and also in $1999($ Alpha $=.534 ; \mathrm{n}=537)$. The 1985 index was subtracted from the 1999 index to create a change in extrinsic work values measure, with higher scores indicating that study participants placed more value on extrinsic work rewards at age 32 compared to age 18 .

\section{Control Variables}

Gender and union membership were included as control variables, since women typically earn significantly less than men while union members generally earn somewhat more than non-members (Krahn, Hughes and Lowe 2015). Hours worked per week (main job) was also included as a predictor of total 1999 income, since this variable is typically the most powerful predictor of variations in income. Hours worked was not included as a control variable for the "quality of employment" analysis, since part-time employment is one of the components of our work quality index.

A binary measure of parents' education (at least one parent with a university degree $=1$ ) was included as an indicator of family socioeconomic status (SES) which could affect study participants' future education, their employment outcomes, and their risk of unemployment. Type of high school program (academic versus vocational) and self-reported grades in Grade 12 (a five-category ordinal measure) were also 
controlled in our analyses, since both are good proxy measures for young people's level of motivation as well as their skills and abilities, factors that might affect their future risk of unemployment.

Youth-adult transition was measured by the number of years since the respondent had left her/his parental home and a (binary) measure indicating whether she/he had become a parent by 1999. Human capital investment, which would be expected to have an effect on both earnings and quality of employment, as well as risk of future unemployment, was measured by the number of years of full-time post-secondary education completed between 1985 and 1999.

\section{Findings}

Study participants who had experienced more unemployment were earning less $(r=-158)$ and employed in poorer quality jobs $(r=-.202)$ at age 32 (Appendix A). Those reporting more unemployment were more likely to experience a decline in self-esteem between age 18 and $32(r=-.131)$, but a similar relationship was not observed for change in perceived control or change in extrinsic work values. Those who had completed an academic high school program reported less unemployment $(r=-.098)$, as did those who had lived away from their parents' home longer $(r=$ $-.092)$, and those who were union members at age $32(r=-.132)$.

Turning to multivariate relationships, Table 2 displays three OLS regression equations in which the social psychological change variables were regressed on months of unemployment between 1985 and 1999 and the nine control variables. Unemployment had a significant negative effect on self-esteem change (Column 2; $\beta=-.145$ ); study participants who reported more unemployment were more likely to report lower selfesteem at age 32 compared to age 18 . Unemployment did not have a significant impact on change in perceived control (Column 1) nor on change in extrinsic work values (Column 3). Consequently, neither of these measures could mediate the scarring effect of unemployment on employment outcomes, and only self-esteem change is included in the final multivariate analyses. 
Table 2: Social-psychological change measures regressed on control variables and unemployment experience (1985-99) ${ }^{1}$

\begin{tabular}{llll}
\hline Independent variables & $\begin{array}{l}\text { Perceived } \\
\text { control } \\
\text { change }(\beta)\end{array}$ & $\begin{array}{l}\text { Self-esteem } \\
\text { change }(\beta)\end{array}$ & $\begin{array}{l}\text { Extrinsic work } \\
\text { value change }(\beta)\end{array}$ \\
Gender (female = 1) & .048 & .004 & -.025 \\
Parent(s' education (degree =1) & .036 & -.017 & .022 \\
Academic HS program (yes = 1) & .105 & .006 & -.070 \\
Average grades in Grade 12 (1985) & -.005 & $-.120^{*}$ & $-.128^{*}$ \\
Hours worked per week (1999 main job) & .105 & .081 & .024 \\
Years since leaving home & .060 & $.111^{*}$ & -.091 \\
Parent by 1999 (yes = 1) & .057 & $.139^{*}$ & -.001 \\
& & & \\
Years FT post-sec education (1985-99) & .025 & .080 & -.217 \\
Union membership (yes =1) & $-.105^{*}$ & -.053 & .063 \\
Months unemployed (1985-99) & -.013 & $-.145 *$ & .033 \\
$\quad\left(\mathrm{R}^{2}\right)$ & $(.036)$ & $(.078)$ & $(.093)$ \\
& & & \\
\hline
\end{tabular}

${ }^{1} N=392$ employed study participants.

$* p<0.05$.

In Model 1 in Table 3, total 1999 income was regressed on the nine control variables which, together, accounted for $40 \%$ of the variation in income $\left(\mathrm{R}^{2}=0.402\right)$. Not surprisingly, since people who work more hours earn more, on average, hours worked has the largest net effect $(\beta=.429)$. As we would expect from previous research, women earned significantly less than men $(\beta=-.251)$, controlling on the other variables in the equation. Table 3 also highlights the expected positive link between investments in human capital and earnings. Graduates of high school academic programs earned significantly more money in 1999 ( $\beta$ $=.148$ ), as did study participants who had received higher grades in their final year of high school $(\beta=.129)$ and those who had completed more years of full-time post-secondary education $(\beta=.123)$. In addition, those who had lived away from home longer earned more $(\beta=.091)$, perhaps reflecting more years in the paid labour force. As previous research has shown, union members earned more $(\beta=.115)$, taking other factors into account. In contrast, parents' education did not have a significant effect after controlling on high school and post-secondary education measures, both of which were positively associated with family SES (Appendix A). Parenthood by age 32 was also a non-significant predictor. 
Table 3: 1999 Total income ${ }^{1}$ regressed on control variables, unemployment experience (1985-99), and self-esteem change (1985-99) ${ }^{2}$

\begin{tabular}{|c|c|c|c|}
\hline Independent variables & Model $1(\beta)$ & Model $2(\beta)$ & Model $3(\beta)$ \\
\hline Gender $($ female $=1)$ & $-.251 *$ & $-.261^{*}$ & $-.261^{*}$ \\
\hline Parent(s)' education $($ degree $=1)$ & .068 & .064 & .064 \\
\hline Academic HS program (yes = 1) & $.148^{*}$ & $.140^{*}$ & $.140^{*}$ \\
\hline Average grades in Grade 12 (1985) & $.129 *$ & $.128 *$ & $.129 *$ \\
\hline Hours worked per week (1999 main job) & $.429 *$ & $.420^{*}$ & $.420 *$ \\
\hline Years since leaving home & $.091 *$ & $.088^{*}$ & $.087 *$ \\
\hline Parent by $1999($ yes = 1) & .047 & .040 & .039 \\
\hline Years FT post-sec education (1985-99) & $.123^{*}$ & $.126^{*}$ & $.126^{*}$ \\
\hline Union membership (yes $=1)$ & $.115^{*}$ & $.098^{*}$ & $.098^{*}$ \\
\hline Months unemployed (1985-99) & & $-.129 *$ & $-.128 *$ \\
\hline Self-esteem change (1985-99) & & & .003 \\
\hline$\left(\mathrm{R}^{2}\right)$ & $(.402)$ & $(.418)$ & $(.418)$ \\
\hline
\end{tabular}

Model 2 in Table 3 adds months of unemployment between 1985 and 1999 to the equation. The increase in variance explained is statistically significant $(\mathrm{p}<.001)$, and a moderate-strength career scarring net effect of unemployment $(\beta=-.129)$ is observed, Specifically, those who had experienced more unemployment reported lower incomes, taking into account the control variables. This translates into about $\$ 18$ less per month at age 32 for every month of unemployment in the previous 14 years (the slope was estimated using total income (all jobs) in its original (not square root transformed) form.

Model 3 (Table 3) attempts to explain this scarring effect by determining if change in self-esteem between 1985 and 1999 mediates the impact of months of unemployment. In other words, does the significant direct effect of unemployment on earnings disappear/decrease after change in self-esteem is added as a predictor? It does not; the coefficient for months of unemployment in Model $3(\beta=-.128)$ is virtually unchanged from Model $2(\beta=-.129)$. Furthermore, self-esteem change does not itself have a direct net effect on 1999 income.

Table 4 replicates the analysis in Table 3 but for paid employees only ( $\mathrm{N}=371$ ), using the $1999 \mathrm{QoE}$ index as the dependent variable. Since full-time employment is one component of this index, hours worked (the 
strongest predictor in Table 3) is omitted as a control variable. Hence, only $10 \%$ of the variation in 1999 quality of employment is accounted for by the eight remaining control variables (Model $1, \mathrm{R}^{2}=0.103$ ). Unemployment during early adulthood has a significant negative effect on paid employees' quality of employment at age 32 (Model 2, $\beta=-.192$ ); study participants who had experienced more unemployment in the years following high school were, on average, working in lower quality jobs.

Table 4: Quality of employment (1999) index regressed on control variables, unemployment experience (1985-99), and self-esteem change (1985-99) ${ }^{1}$

\begin{tabular}{|c|c|c|c|}
\hline Independent variables & Model $1(\beta)$ & Model $2(\beta)$ & Model $3(\beta)$ \\
\hline Gender $($ female $=1)$ & $-.137 *$ & $-.148^{*}$ & $-.146^{*}$ \\
\hline Parent(s)' education $($ degree $=1)$ & -.018 & -.023 & .022 \\
\hline Academic HS program $($ yes $=1)$ & .107 & .092 & .093 \\
\hline Average grades in Grade 12 (1985) & .092 & $.099 *$ & $.109^{*}$ \\
\hline Years since leaving home & $.186^{*}$ & $.177^{*}$ & $.170^{*}$ \\
\hline Parent by $1999($ yes = 1) & $-.176^{*}$ & $-.192 *$ & $-.197^{*}$ \\
\hline Years FT post-sec education (1985-99) & .013 & .01 & .008 \\
\hline Union membership $($ yes $=1)$ & .096 & .064 & .064 \\
\hline Months unemployed (1985-99) & & $-.192 *$ & $-.185^{*}$ \\
\hline Self-esteem change (1985-99) & & & .053 \\
\hline$\left(\mathrm{R}^{2}\right)$ & $(.103)$ & (.138) & $(.140)$ \\
\hline
\end{tabular}

The addition of self-esteem change in Model 3 leads to only a small decline in the net effect of unemployment; it continues to be negatively associated with quality of employment (Model 3, $\beta=-.185$ ). The additional variance explained is non-significant. The direct effect of self-esteem change is also non-significant (Model 3, $\beta=.053$ ). As we observed for total 1999 income (Table 3), self-esteem change does not mediate the career-scarring effect of unemployment on quality of employment. For both dependent variables, our core hypothesis is not supported.

High school program and years of post-secondary education do not have significant effects in Table 4, as they did in the total income analysis (Table 3), perhaps reflecting the fact that part-time and temporary work (two central components of the QoE index) have become very common among young workers, including those with post-secondary education. In contrast, the two youth-adult transition variables now have signifi- 
cant net effects (Model 3). Study participants who had been living away from their parents longer reported better jobs $(\beta=.170)$, perhaps because they entered the adult labour market earlier. In contrast, those who were parents themselves by age 32 reported less desirable jobs $(\beta=-0.197)$. Parents, particularly women, may be choosing to work part-time while their children are young.

\section{Conclusions}

This longitudinal study clearly demonstrates that youth unemployment has a scarring effect on early adult careers, whether measured by income (as in most previous studies) or by quality of employment (for paid employees only). Controlling on a wide range of other relevant variables, our analyses show that more unemployment between the ages of 18 and 32 is associated, on average, with lower incomes and job quality at age 32. This study also asks whether changes in self-esteem, perceived control, and extrinsic work values mediate the effect of youth employment on later career outcomes. We find no support for this plausible hypothesis emerging from the unemployment and mental health literature.

As noted earlier, most scarring studies have assumed that labour market mechanisms (i.e., human capital depreciation, reduced social capital, employer discrimination) explain the phenomenon, even though there have been very few, if any, direct tests of such explanations. Nevertheless, several recent non-longitudinal studies suggest that signaling theory may provide a useful explanation of career scarring.

A 2012 survey of hiring managers revealed that they were actually more inclined to hire someone with a criminal record than someone who had been unemployed for more than two years (Huffington Post 2012). A 2011 analysis of ads posted on US hiring websites found a large number explicitly stating that applications would only be accepted from currently employed applicants (National Employment Law Project 2011). Equally telling are results from Kroft et al.'s (2012) field experiment that distributed fictitious resumes to employers advertising on-line. The researchers monitored how often employers called to arrange an interview, and in response to which types of resumes, and reported that employers discriminate (i.e., are less likely to call for an interview) against job applicants with longer records of unemployment.

Absent support for social psychological explanations of career scarring in our study, along with evidence from elsewhere that employers might be discriminating against the previously unemployed, has important policy implications. It is important, of course, to encourage un- 
employed youth to continue to seek jobs or better jobs, and to obtain further training. But efforts to solve the problem of youth unemployment that focus on a presumed "culture of dependency" among jobless young people, such as those recently proposed by Prime Minister David Cameron in the UK (Beattie, 2015), are likely missing the target. Our findings, and the limited research on employer discrimination, suggests that rather than focusing on the psyches of the unemployed we should turn our attention towards, and target our policy initiatives at, the labour market and employers (Smyth 1999). Educational campaigns targeting potential employers are an obvious policy proposal. Tax incentives to hire youth, including the formerly unemployed, might be particularly effective. Human rights legislation could be used to penalize employers who do discriminate, if evidence were available.

Our findings are from a study completed 15 years ago, but they remain important today. As Bernard (2013) shows, current (2010-12) Canadian youth unemployment rates are as high as they were in 1985 and 1992 when our study participants were experiencing unemployment that, by 1999, had scarred their careers. Bell and Blanchflower (2011) discuss similarly high youth unemployment rates in other countries, particularly during the Great Recession (2007-9). Although our sample was comprised of western Canadian urban youth leaving high school in 1985, we believe our findings can be generalized to urban youth today in other parts of Canada and much of the US, but perhaps not to Europe or developing countries where institutional and economic differences might lead to different outcomes. We also believe that the policy implications of our study are as valid today as they were at the end of the last century.

\section{Future Research}

Further longitudinal research to test our prediction that youth unemployment continues to have scarring effects today would be very useful. An analysis of unemployment's possibly different effects on women's and men's careers would be also be informative, particularly if it took into account what is essentially another form of scarring, the "motherhood penalty" (Budig and Hodges, 2010) that contributes to the gender wage-gap. In addition, qualitative research focusing on the experiences of young (and older) unemployed labour force participants could add a great deal to our understanding of this phenomenon.

We were unable to test labour market-focused explanations of the career scarring effects of youth unemployment, but future research that directly links employer and job applicant data would be very useful. Such research might be able to further differentiate among the alterna- 
tive labour market-focused hypotheses discussed in the literature, namely, human capital depreciation, social capital deficits, and employer discrimination. Studies testing social psychological explanations of career scarring among older workers would also be useful.

\section{Limitations}

It is possible that evidence of social psychological mediating effects would be observed in a longitudinal study of adults (compared to youth) and in studies (of youth or adults) that analyzed data from more than two time points. Rural youth were not part of our sample, so our findings may be generalizeable only to urban youth, although we believe that they would apply to urban youth across Canada and many parts of the US.

High school dropouts were not included in our baseline (1985) study. Previous research (e.g., Tanner, Krahn, and Hartnagel 1995) has shown that, compared to high school graduates, dropouts are more likely to experience unemployment over the course of their careers. Sample attrition in this study may mean that baseline study participants who experienced more unemployment between age 18 and 32 were less likely to participate in the 1999 follow-up survey. It is also possible that our retrospective measure of unemployment led to some respondents forgetting spells of unemployment they had experienced much earlier (Jacobs 2002). All three of these limitations, however, could also mean that this study underestimates the scarring effect of youth unemployment on career outcomes at age 32 .

\section{REFERENCES}

Antonini, Matteo and Felix Bühlmann. 2015. "Towards a multi-dimensional theory of post-unemployment scarring: Recurrence, instability and downgrading." University of LausanneL NCCR Lives Working Paper 2015/37.

Arulampalam, Wiji. 2001. "Is unemployment really scarring? Effects of unemployment experiences on wages." The Economic Journal 111: F585F606.

Beattie, Jason. 2015. "David Cameron aims to force unemployed youths to do community work before they get benefits." Daily Mirror Online, 17 February. http://www.mirror.co.uk/news/uk-news/david-cameron-aimsforce-unemployed-5175390 [access date: July 21, 2015]

Bell, David N.F. and David G. Blanchflower. 2011. "Young people and the great recession." Oxford Review of Economic Policy 27(2): 241-267.

Bernard, André. 2013. "Unemployment dynamics among Canada's youth.” Economic Insights, no. 024. Statistics Canada Cat. no. 11-626-X. 
Brand, Jennie E. 2006. "The effect of job displacement on job quality: Findings from the Wisconsin Longitudinal Study." Research in Social Stratification and Mobility 24: 275-298.

Breslin, F. Curtis and Cam Mustard. 2003. "Factors influencing the impact of unemployment on mental health among young and older adults in a longitudinal, population-based survey." Scandinavian Journal of Work, Environment \& Society 29(1): 5-14.

Budig, Michelle and Melissa Hodges. 2010. "Differences in disadvantage: Variations in the motherhood penalty across white women's earnings distributions." American Sociological Review 75(5): 705-728.

Burgess, Simon, Carol Propper, Hedley Rees and Arran Shearer. 2003. "The Class of 1981: The effects of early career unemployment on subsequent unemployment experiences." Labour Economics 10: 291-309.

Chung, Lucy. 2006. "Education and earnings." Perspectives on Labour and Income 18(3): 28-35.

Clark, Andrew E., Yannis Georgellis and Peter Sanfey. 2001. "Scarring: The psychological impact of past unemployment." Economica 68: 221-41.

Clark, Andrew. E. 2005. "What makes a good job? Evidence of OECD countries." Pp. 11-30 in Stephen Bazen, Claudio Lucifora and Wiemer Salverda, eds. Job Quality and Employment Behaviour. London: Palgrave Macmillan.

Cockx, Bart, and Matteo Picchio. 2012. "Scarring effects of remaining unemployed for long term unemployed school-leavers." Journal of the Royal Statistical Society: Series A (Statistics in Society), 176(4): 951-980.

Cruces, Guillermo, Andrés Ham and Mariana Viollaz. 2012. "Scarring effects of youth unemployment and informality: Evidence from Argentina and Brazil." La Plata, Argentina: Center for Distributive, Labor and Social Studies. http://www.iza.org/conference files/YULMI2012/viollaz_m8017. pdf [access date: July 22, 2015]

Dieckhoff, Martina. 2011. "The effect of unemployment on subsequent job quality in Europe: A comparative study of four countries." Acta Sociologica 54(3): 233-249.

Dooley, David, Jonathan Fielding and Lennart Levi. 1996. "Health and unemployment." Annual Review of Public Health 17: 449-65.

Dooley, David, Joann Prause and Kathleen A. Ham-Rowbottom. 2000. "Underemployment and depression: Longitudinal relationships." Journal of Health and Social Behavior 41: 421-36.

Empson-Warner, Susan and Harvey Krahn. 1992. "Unemployment and occupational aspirations." A panel study of high school graduates." Canadian Review of Sociology and Anthropology 29: 38-54. 
Fergusson, David M., L. John Horwood and Lianne J. Woodward. 2001. "Unemployment and psychosocial adjustment in young adults: Causation or selection.” Social Science \& Medicine 53(3): 305-320.

Fevre, Ralph. 2011. "Still on the scrap heap? The meaning and characteristics of unemployment in prosperous welfare states." Work, Employment \& Society 25(1): 1-9.

Franzen, Eva M. and Anders Kassman. 2005. "Longer-term labour market consequences of economic inactivity during young adulthood: A Swedish national cohort study." Journal of Youth Studies 8: 403-424.

Fryer, David 1997. "International perspectives on youth unemployment and mental health: Some central issues." Journal of Adolescence 20(3): 333342.

Gallie, Duncan, Serge Paugam and Sheila Jacobs. 2003. "Unemployment, poverty and social isolation: Is there a vicious circle of social exclusion?" European Societies 5(1): 1-32.

Gangl, Markus. 2004. "Welfare states and the scar effects of unemployment: A comparative analysis of the United States and West Germany." American Journal of Sociology 109(6): 1319-1364.

Gangl, Markus. 2006. "Scar effects of unemployment: an assessment of institutional complementarities." American Sociological Review 71(6): 9861013.

Gardecki, Rosella and David Neumark. 1998. "Order from chaos? The effects of early labour market experiences on adult labour market outcomes." Industrial \& Labor Relations Review 51(2): 299-322.

Goldsmith, Arthur H., Jonathan R. Veum and William Darity Jr. 1996. “The impact of labour history on self-esteem and its component parts, anxiety, alienation and depression." Journal of Economic Psychology 17: 183220.

Gregg, Paul and Emma Tominey. 2005. "The wage scar from male youth unemployment." Labour Economics 12: 487-509.

Hammer, Torild. 1997. "History dependence in youth unemployment." European Sociological Review 13(1): 17-33.

Hartnagel, Timothy F. and Harvey Krahn. 1995. "Labour market problems and psychological well-being: A panel study of Canadian youth in transition from school to work." British Journal of Education and Work 8(3): 3353.

Huffington Post Canada. 2012. "Long-term unemployment worse than a criminal record when it comes to job placement: Survey." (8 November, 2012): http://www.huffingtonpost.com/2012/09/18/long-term-unemploymentworse-than-criminal-record-_n_1893571.html? [access date: July 22, 2015]. 
Jacobs, Sheila C. 2002. "Reliability and recall of unemployment events using retrospective data." Work, Employment \& Society 16(3): 537-48.

Jahoda, Marie. 1982. Employment and Unemployment: a Social-Psychological Approach. Cambridge: Cambridge University Press.

Johnson, Monica L. 2002. "Social origins, adolescent experiences, and work value trajectories during the transition to adulthood." Social Forces 80(4): 1307-1341.

Krahn, Harvey.J., Karen D. Hughes and Graham S. Lowe. 2015. Work, Industry, and Canadian Society. $7^{\text {th }}$ ed. Toronto: Nelson.

Krahn, Harvey. J., Andrea L. Howard and Nancy L. Galambos. 2015. “Exploring or floundering: The meaning of educational and employment fluctuations in emerging adulthood." Youth \& Society 47(2): 245-266.

Kroft, Kory, Fabian Lange and Matthew J. Notowidigdo. 2012. "Duration dependence and labor market conditions: Theory and evidence from a field experiment." Canadian Labor Market and Skills Researcher Network (CLMSRN) Working Paper no. 101.

Lamba, Navjot K. 2003. "The employment experiences of Canadian refugees: Measuring the impact of human and social capital on quality of employment." Canadian Review of Sociology 40 (1): 45-64.

Luijkx, Ruud and Marten H.J.Wolbers. 2009. "The effects of non-employment in early work-life on subsequent employment chances of individuals in the Netherlands.” European Sociological Review 25(6): 647-660.

Marquardt, Richard 1998. Enter at Your Own Risk: Canadian Youth and the Labour Market. Toronto: Between the Lines.

McVey, Wayne Jr. and Warren Kalbach. 1995. Canadian Population, Scarborough, ON: Nelson Canada.

Mossakowski, Krysia N. 2009. "The influence of past unemployment duration on symptoms of depression among young women and men in the United States." American Journal of Public Health 99(10): 1826-32.

Mroz, Thomas A. and Timothy H. Savage. 2006. "The long-term effects of youth unemployment." Journal of Human Resources 41(2): 259-93.

Murphy, Gregory C. and James A. Athanasou. 1999. "The effect of unemployment on mental health." Journal of Occupational and Organizational Psychology 72: 83-99.

National Employment Law Project. 2011. "Hiring discrimination against the unemployed: Federal bill outlaws excluding the unemployed from job opportunities, as discriminatory ads persist." http://big.assets.huffingtonpost.com/unemployedhiring.pdf [access date: July 22, 2015]

Patterson, L. J. Meân. 1997. "Long-term unemployment among adolescents: A longitudinal study." Journal of Adolescence 20(3): 261-280. 
Paul, Karsten I. and Klaus Moser. 2009. "Unemployment impairs mental health: Meta-analyses.” Journal of Vocational Behavior 74(3): 264-282.

Pearlin, Leonard I. and Carmi Schooler. 1978. "The structure of coping." Journal of Health and Social Behavior 19: 2-21.

Pollman-Schult, Matthias and Felix Buchel. 2005. "Unemployment benefits, unemployment duration and subsequent job quality." Acta Sociologica 48(1): 21-39.

Prause, JoAnn and David Dooley. 1997. "Effect of underemployment on schoolleavers' self-esteem." Journal of Adolescence 20(3): 243-260.

Rosenberg, Morris. 1979. Conceiving the Self. New York: Basic Books.

Ryan, Paul. 2001. "The school to work transition: A cross national perspective." Journal of Economic Literature 39: 34-92.

Schmelzer, Paul. 2011. "Unemployment in early career in the UK: A trap or a stepping stone?" Acta Sociologica 54(3): 251-265.

Shanahan, Michael J. 2000. "Pathways to adulthood in changing societies: Variability and mechanisms from a life course perspective." Annual Review of Sociology 26: 667-92.

Smyth, John. 1999. "Schooling and enterprise culture: Pause for critical policy analysis." Journal of Educational Policy 14: 435-444.

Tabachnick, Barbara G. and Linda S. Fidell. 2007. Using Multivariate Statistics. ( $5^{\text {th }}$ ed.). Boston: Allyn and Bacon.

Tanner, Julian, Harvey Krahn and Timothy F. Hartnagel. 1995. Fractured Transitions from School to Work: Revisiting the Dropout Problem. Don Mills, ON: Oxford University Press.

Wanberg, Connie R., Theresa M. Glomb, Zhaoli Song and Sarah Sorenson. 2005. "Job search persistence during unemployment: A 10-year longitudinal study." Journal of Applied Psychology 90: 411-30.

Harvey Krahn is a Professor of Sociology at the University of Alberta. His research interests are in social inequality, work and education, immigration, political sociology, environmental sociology, and research methods.

Email: harvey.krahn@ualberta.ca

Angela Chow is an Assistant Professor in the Department of Applied Health Science at Indiana University. Her research focuses on work values and task values, and how these values shape developmental pathways from adolescence to young adulthood and midlife, with particular emphasis on outcomes related to education, career, and well-being

Email: chowa@indiana.edu 


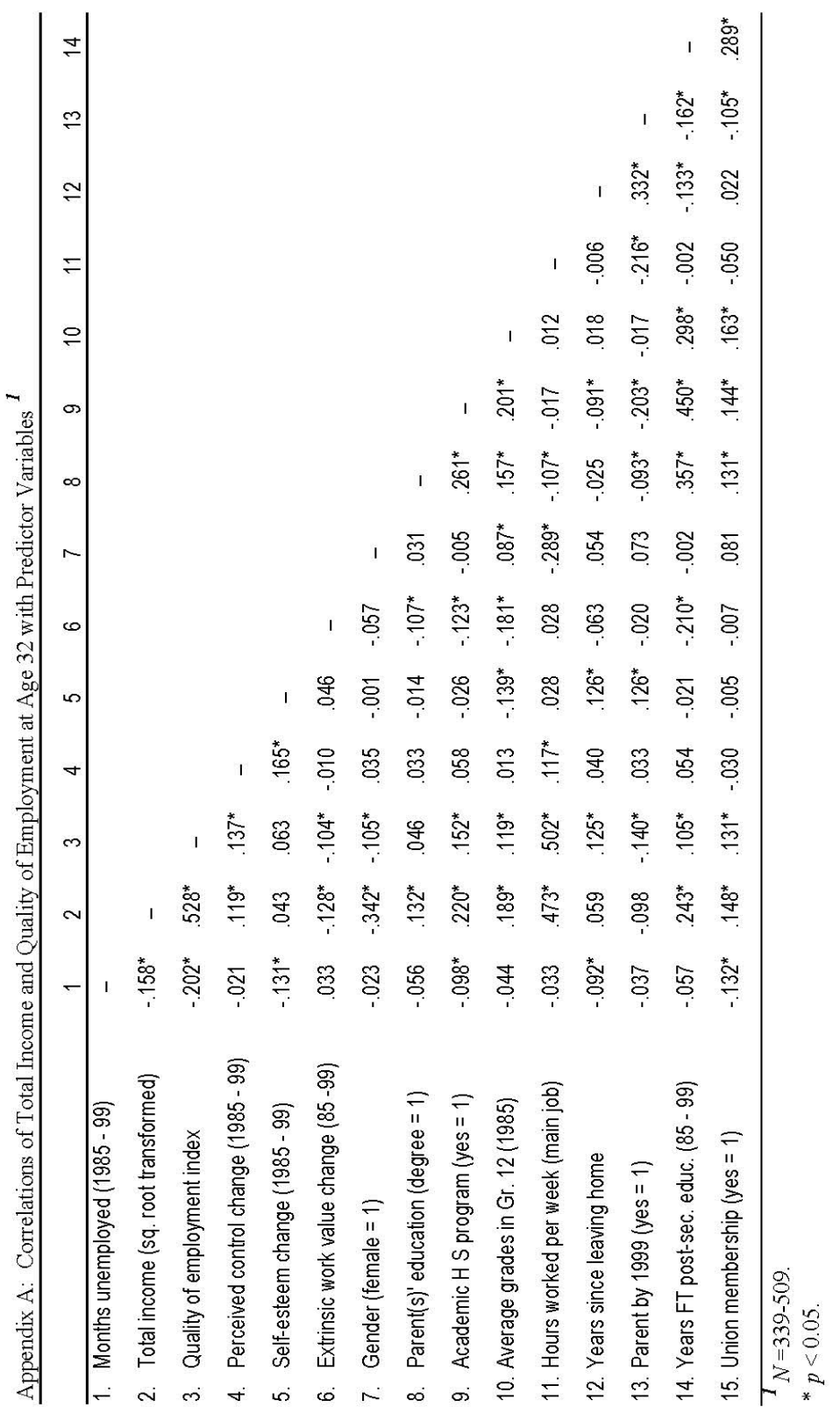


138 (C) Canadian Journal of Sociology/Cahiers Canadiens de sociologie 41(2) 2016 